\title{
Commercial predictive testing: the desirability of one overseeing body
}

Rogeer Hoedemaekers School of Medical Sciences, KUN Nijmegen, the Netherlands

\begin{abstract}
In Europe a process of harmonisation of standards and regulations on genetic testing has started. Public discussion and consultation are recommended, but it is not clear in every European country how the decision making process as regards the further introduction of genetic testing services should be formed. In this paper the usefulness and importance of an overseeing body for genetic screening and testing is founded on four lines of reasoning: (1) analysis of the role of value judgments in the use of the concept of (genetic) abnormality; (2) a balancing of potential benefits for all parties involved; (3) a balancing of potential disadvantages, and (4) the greater availability of commercial genetic tests in the future. It is further argued that such an overseeing body has advantages for all the interested parties.

(Fournal of Medical Ethics 2000;26:282-286)
\end{abstract}

Keywords: Genetic testing; commercialisation; normality; overseeing body

The Council of Europe urges that society's views must be ascertained on fundamental questions raised by the life sciences and recommends appropriate public discussion and consultation. ${ }^{1}$ The introduction of predictive genetic testing services also raises difficult policy issues. ${ }^{2}$ One possibility is to leave the use of genetic tests and testing services to market forces. Others plead for regulation of these services and a combination of these two possibilities is also envisaged. ${ }^{34}$ But who is going to decide? Four lines of argumentation are used to support the view that criteria for the introduction of predictive genetic tests or testing services should not be decided by suppliers, health professionals or consumers only, but by a permanent national overseeing body involving all interested parties.

\section{Normality and abnormality}

A predictive genetic test offers (apparently) healthy individuals an opportunity to detect a "genetic abnormality", either in themselves or in their offspring. This concept tends to be used in the case of a link between a mutation in the DNA materia and future deleterious effects. ${ }^{5}$ For some diseases the role and function of the mutation in the causal disease-path is well understood, for others no full causal explanation can be given. Many genetic mutations have a wide (and often unpredictable) range of severity and not every "abnormality" at the DNA level generates "abnormal" degrees of suffer- ing. And sometimes, as in the case of Huntington's disease, it takes a long time before the "abnormal" gene expresses itself clinically. Before that time the individual with the genetic "abnormality" can usually lead a normal life. So the question arises by which standards a genetic mutation is termed abnormal. Assuming that the concept of abnormality is linked with deleterious effects, we can distinguish effects of a genetic mutation in several domains: biological, psychological/psychosocial and societal.

The biological domain comprises three major functional levels where effects of changes in the DNA material manifest themselves. Structural changes at DNA level can affect the structure of the protein they code for, and this may lead to different protein characteristics, which may or may not affect physiological functioning. Different physiological functioning may in it its turn lead to more easily observable clinical effects, as in the thalassaemias or sickle-cell disease. For many physiological processes medical practice has established normal and abnormal values which can serve as reference standards to judge the effects of changes at DNA and protein level. In some cases medical experience has already established which values can be associated with serious clinical conditions, but often the precise disease path is not known (yet), as in hereditary breast cancer. In such a situation clinical manifestations are statistically associated with DNA sequences (for example BRCA1 and BRCA2), and a strong statistical relation between a particular DNA sequence and certain clinical effects can be reason to call a DNA sequence abnormal. It is obvious that in this biological domain geneticists and other medical professionals have the expertise to determine standards of (ab)normality.

DNA mutations can have a (variable) effect on an individual's psychological or psychosocial functioning (for example fragile X-syndrome, cystic fibrosis). The normality (acceptability) or abnormality (unacceptability) of these kind of visible effects will usually not be determined by medical professionals only, but also by individual judgment of an acceptable or unacceptable burden of the harmful effects by the test subject, parents or family. Assessment of abnormality is usually based here on individual experiences, lifestyle, beliefs and coping abilities and on personal standards (either a minimum, average or ideal norm). 
Furthermore there are effects of a harmful condition in terms of a burden on society: the care and support needed for those suffering from a genetic condition. Here assessment of the normality and abnormality of the burden of treatment (in economic terms) influences decisions in health care policy, as, for example, the B-thalassaemia screening programme in Cyprus. ${ }^{6}$

Medical professionals and individual test subjects do not live in a vacuum, however, and collective beliefs of a community or group, based on shared experiences and perceptions will also influence judgment of what is a normal or abnormal burden of harmful effects. There can, for example, be differences between individuals who are familiar with a specific condition and those who are not. Non-patients tend to see only the negative effects of the condition, and may use different reference standards from patients, who may also point to possibilities of which non-patients are unaware. And beliefs about what constitutes minimal (or maximum) human happiness and/or wellbeing in a community will inevitably affect the judgment of abnormality made by medical professionals as well as potential users. ${ }^{7}$ It will also have an effect on suppliers of genetic tests: these collective standards of normality and abnormality will help them determine whether there is a market for a specific genetic test or testing service.

\section{Collective standards}

So when determining the abnormality of a specific condition several important groups play a role: medical professionals, potential test subjects, patients, public (health) authorities and suppliers. This already indicates that each of them should have a say about the question whether a specific genetic test or testing service ought to be introduced or not. To a certain degree these groups influence one another. For example, geneticists are urged by patient groups, or the degree of societal stigma attached to a given condition, to go in search of the gene believed to have an influence on it. Providers of tests may be led by collective standards of normality and abnormality and the way in which a specific condition is evaluated in a community or society. Potential test subjects may be influenced by societal evaluation, professional enthusiasm or educational and/or informational programmes drawn up by health authorities..$^{5}$ This interrelation of value judgments suggests there is no such thing as a completely subjective and private assessment of the burden and suffering of a condition.

\section{Benefits}

There are not only benefits for potential test subjects, but also for other interested parties. ${ }^{8}$ Perceived community benefits, for example, are: reduction of the incidence of disease, improvemen of public health and improvement of health of future generations. A further benefit is reduction of the burden of disease for society: genetic screening can lead to a reduction of health care costs.
Health care institutions expect to reduce expenses because of enhanced efficiency and timely intervention. Also insurance companies foresee benefits. They can use genetic tests to calculate better the risk an individual has of developing a disease. Employers may wish to know if their employees are susceptible to a work-related illness, or an illness which may impair work performance, in order to enhance efficiency and profit. For commercial suppliers of genetic tests profit is an important benefit.

For test subjects major perceived benefits are enhancement of health, psychological wellbeing, and autonomy. Testing may help alleviate (future) physical suffering of their family and children. It is thought to bring greater psychological wellbeing. It can create more certainty or reassurance, less anxiety in procreation, and it can help a person to make important life choices. It is said to offer individuals a greater degree of control over their lives.

Finally, for health professionals working on a feefor-service basis, genetic testing services can bring an increased income.

Who, then, is to determine which benefits, for test subjects, for the market and for health care itself, are to be decisive in decisions about the introduction of a test? Sometimes interests are shared, but this need not necessarily be the case. Emphasis on economic advantages for suppliers, employers and insurers, for example, need not always benefit test subjects or-in the long run-the community or health care. ${ }^{9}$ Fairness demands that the various interests are weighed and balanced and the only democratic way to do this properly is to bring all the interested parties together.

\section{Potential harm}

Genetic screening and testing can generate harm at the community, institutional and individual level. These potential dangers depend on the type of test that is offered (carrier screening for autosomal recessive conditions, autosomal dominant and X-linked conditions, or susceptibility tests), and the time of testing (for example, preconceptional or prenatal). Effects perceived at the community level are: discrimination against population groups where a certain hereditary disease is more prevalent, social pressure to participate in genetic screening programmes or a greater tendency to hold parents responsible for the suffering of their children.

At the institutional level negative economic effects are that genetic screening and testing may lead to more follow up testing, prevention or intervention, and, hence, to an increase in health care costs. ${ }^{10}$

Perceived dangers for individuals are the generation of anxiety or confusion and feelings of guilt or regret in the case of non-participation. Prenatal screening can cause physical damage to the future child. It can lead to difficult and agonising choices and stress and it can give a test subject a false sense of security. ${ }^{11}$ Unanticipated genetic information (for example about non-paternity) can also have negative effects on the family. ${ }^{12}$ Failure to keep up a change of lifestyle after learning about a genetic 
susceptibility to disease may cause stress or lower self esteem. ${ }^{10}{ }^{11}$ And negative effects of genetic testing of children are: greater parental concern with negative psychological effects for the child; stress because of knowledge of a late-onset disease, psychological damage as a result of self stigmatisation, and/or stigmatisation by family-members. ${ }^{13}$

Finally, there are threats to autonomy: familymembers of persons screened may not wish to know the results, but may learn inadvertently about the results. Their right (not) to know may be violated.

This potential for harm at various levels also raises the question whether we should let impersonal market forces decide which tests are placed on the market.

\section{Commercial genetic testing}

Until recently private companies and genetic testing laboratories have mostly offered their tests and testing services through specialist care. They may try to expand their market by offering tests and services through primary care or direct to the public. Greater availability of commercial genetic tests and testing services is believed to bring benefits. They enhance autonomy and free choice: any person who wishes to know about his or her health risks can learn about them. They offer an extra opportunity to avoid future suffering. Yet there are also negative effects. An extra workload for primary carers, for example, or inadequate information and counselling about the value of a test, its reliability, benefits and potential for harm. ${ }^{14}$

When a test is offered to the public (for example through mail or internet services) there are even more negative effects for test subjects. ${ }^{15}$ If they are not covered by national or private insurance these tests can be expensive, even more so if pre- and post-test counselling is included or if more familymembers have to be tested. This can lead to unequal access, which is undesirable, especially in the case of people who are at approximately equal risk of getting a serious disease. Also, there is a greater danger of inadequate pretest information and misunderstanding of the test result. And will important information always reach medical profesionals? It is also possible that tests will be offered whose predictive value and/or reliability is not (yet) adequate. Also, protection of privacy may be more problematic. There is no certainty that the requirements for health professionals and health institutions will be followed.

For health care institutions greater availability of genetic tests can lead to a considerable extra burden, as it will lead to greater demand for follow up testing, counselling and intervention. Especially in the case of large scale use of predictive genetic tests there is a possibility that follow up services cannot always be provided. ${ }^{16}$

For insurers there is uncertainty whether greater availability of genetic tests will eventually lead to a reduction of their expenses. Besides, through direct genetic testing test subjects can acquire extra risk information. If this is not passed on to insurers it may lead to adverse selection.

\section{A free market?}

There is consensus that predictive genetic screening and testing for medical purposes is an important aim. There are also non-medical benefits, such as "reassurance" in the case of a negative test result or "certainty" in the case of a positive test result. Another benefit is enhancement of autonomy, as genetic information enables a person to make important life choices. Until recently genetic tests and services have been mainly offered as part of medical practice, including tests performed for reassurance and for the enhancement of autonomy. The introduction of commercial genetic tests raises the question: which tests ought to be offered (and paid for) through health care, and which tests ought an individual to pay for him/herself? In view of limited health care resources it could be decided that not all the aims of genetic testing are equally important. This can have consequences for the payment of these genetic tests.

There is consensus that the condition to be tested should constitute a serious health problem, but there is no general agreement as to what this is. Therefore medical professionals tend to leave decision making here to the individual's perception of what constitutes serious suffering. Another criterion is that a test should be offered when there is a considerable degree of certainty that a specific DNA sequence(s) will lead to serious suffering. Yet genetic testing is often done on the basis of "perceived risk" and individual attitudes towards risk-taking. This tendency to let the potential test subject decide on the basis of perceived severity and perceived risk could become a costly one for health care.

\section{Strict criteria}

Theoretically, free genetic tests and testing services create the possibility of having a test even if it is not medically indicated; if there are no therapeutical or preventive options; if there is no clear medical benefit; if it does not test for a serious disorder; if there is no adequate predictive value, or if there is uncertainty about the actual "burden" of a condition. For tests offered through health care strict criteria could be devised. However, should other tests not meeting these standards be completely forbidden, provided that adequate information is given about the test and its value and provided there is (still) a market for such a test? An anxious person could demand a test, even if it does not bring sufficient certainty. This matter is not wholly hypothetical. In the past professional groups have opposed the introduction of certain tests, for example for Alzheimer's disease, because they did not meet their standards. ${ }^{17}$ Genetic breast cancer screening is still controversial, not only because of doubts about the value of the test, but also because of doubts about the preventive options. Yet genetic testing for BRCA1 and BRCA2 mutations have been placed on the market.

Although a completely free market for commercial genetic tests and services seems an attractive option in a liberal climate, the disadvantages for various interested parties reveal that this might not 
be the best option. On the other hand, a complete ban on commercial tests is probably not necessary, as not all types of tests offer the same potential for harm. Nor do they present the same sort of counselling problems.

\section{Who decides?}

Many parties are involved in assessment of the severity of a disease, and the normality or abnormality of a specific genetic condition can be judged by many different standards. There are different advantages and disadvantages of predictive genetic tests and services for various interested parties and this also holds for more easily available genetic tests and services offered through primary care or direct to the public. Therefore decisions about the availability of predictive genetic tests and decisions for their regulation should not be decided by suppliers, consumers or health professionals only.

Fost points out that in the US mass screening programmes have often been driven in the past by political considerations. According to him "policy should include review by those without vested interests, including representatives from the communities most affected". ${ }^{18}$ Although it seems difficult to find any party without a vested interest, the point Fost makes is important. An adequate review system could be useful. Wilfond and Nolan note that US policy as regards genetic screening and testing has had a rather ad hoc quality. They distinguish between two different health policy models: an extemporaneous model and an evidentiary model The former model relies on an independent market where professional practice, legal and consumer forces largely determine utilisation and reimbursement. The latter relies on a rational analysis of scientific data, use of substantive criteria and public participation in the formulation and evaluation of underlying normative issues. ${ }^{3}$ In the case of genetic tests offered direct to the public the provider may wish to decide about the marketing of a test. In the case of genetic services offered through health care there is another interested party: the health professional who offers the test. As reimbursement of genetic services is an important factor influencing consumer choice, health insurers are a third important party with an interest. Together they may exert considerable influence on potential consumers.

This may not provide optimal protection for the consumer or other interested parties against all the disadvantages mentioned above. A more complete overseeing body can take on the task of developing precise and concrete criteria for introduction. Where so many interested parties are involved, introduction of tests and criteria for introduction acceptable to all can only be developed in cooperation. To carry out this task a national overseeing body seems the most suitable and feasible, not only because of national differences in health care systems, health care budgets, national and private insurance systems, reimbursement policies and possibilities for follow up, but also because of different health care priorities and differences in community views as regards the burden and stigma associated with specific genetic conditions.

Ideally, the following parties ought to be represented in a national overseeing body: public health and government authorities; professional organisations (specialists and primary carers); providers; health insurers, and potential consumers (for example by patient and support groups, disability organisations or community leaders and ethicists). They can try to reach consensus on further regulation. ${ }^{19}$ The most important argument for such a consensus model is that it may counterbalance a one-sided approach or manipulation of one or more of the parties having an interest. Differences in risk perception, diverging views as regards the perceived potential harm and the "abnormality" of a specific gene-influenced or gene-determined condition may further support the inclusion of the various parties mentioned earlier in an overseeing body. It seems particularly important to include also the views and perceptions of the handicapped and the chronically ill, who might support less perfect standards of abnormality and may therefore help present more balanced standards.

Such an overseeing body offers various advantages:

1. An overseeing body will facilitate agreement on reference standards aimed at judging the abnormality of the burden of a genetic condition.

2. It will contribute to more complete balancing of advantages and disadvantages for individuals, health care system and community. This can be done on a case by case basis, covering the assessment of the information, interpretation and counselling problems of a specific predictive genetic test.

3. It may counterbalance an overemphasis on economic interests of various parties.

4. It may help commercial providers of genetic screening and diagnostic services decide whether there is a market for a specific genetic test.

5. It can contribute to greater agreement on reimbursement issues and help avoid discrepancies in the assessment of the economic burden of gene-determined or gene-influenced conditions for insurers.

6. A consensus model may help take into account facilities for follow up.

7. It may facilitate decision making by inclusion of societal possibilities for support, care and integration of individuals with a genetic condition.

8. As far as public health institutions are concerned it offers a better opportunity to foresee and plan follow up services and the support and training of extra personnel.

9. If this overseeing body monitors educational and promotional material there could be greater certainty about adequate information on specific genetic tests. 


\section{Conclusion}

Directive 98/79/EC on in vitro diagnostic medical devices - which includes genetic tests and self tests - is mainly concerned with the safety and performance of the product and protection of the health of those working with it. It is less concerned with the manner in which genetic testing services (including test interpretation and counselling are promoted and carried out. ${ }^{20}$ The directive states, however, that manufacturers who place tests and testing devices on the market shall notify the competent authorities of the member states ${ }^{21}$ of the product, its quality and performance. This makes it possible for national overseeing bodies to monitor the new developments regarding predictive genetic testing. The interrelation and interaction of value judgments with respect to the burden of a genetic condition and its treatment for individual, family, health care or society, plus the need to balance the benefits and dangers for the different interested parties, together with the advent of commercial genetic testing services, justifies the establishment of a national overseeing body with the task of proposing and enforcing regulations acceptable to all interested parties.

\section{Acknowledgements}

I am grateful to the Commission of the European Communities for funding the EUROSCREEN II project of which this paper forms a part.

Rogeer Hoedemaekers is Research Fellow in the Department of Ethics, Philosophy and History of Medicine, School of Medical Sciences, KUN Nijmegen, the Netherlands.

\section{References and notes}

1 Council of Europe. Explanatory report to the convention for the protection of human rights and dignity of the human being with regard to the application of biology and medicine: Convention on human rights and biomedicine. Strasbourg: Directorate of Legal Affairs (DIR/JUR (97) 1, 1997.

2 Focus is on predictive genetic tests in (apparently) healthy persons, not on diagnostic genetic testing of patients for better sons, not on diagnostic genetic testing of patients
prognosis, treatment or other forms of intervention.
3 Wilfond B, Nolan K. National policy development for the clinical application of genetic diagnostic technologies. Fournal of the American Medical Association 1993;270:2948-54.

4 Advisory Committee on Genetic testing. Code of practice and guidance on human genetic testing services supplied direct to the public. London: Health Departments of the United Kingdom, 1997.

5 Hoedemaekers R, ten Have $\mathrm{H}$. The concept of abnormality in medical genetics. Theoretical Medicine and Bioethics 1999;20: $537-61$.

6 Hoedemaekers R, ten Have H. Geneticisation: the Cyprus paradigm. Fournal of Medicine and Philosophy 1998;23:274-87. 7 Nordenfelt L. On the nature of health. An action-theoretic approach. Dordrecht, Boston, London: Kluwer Academic Publishing, 1995.

8 Hoedemaekers R. Genetic screening and testing: a moral map. In: Chadwick R, Shickle D, ten Have H, Wiesing U, eds. The ethics of genetic screening. Dordrecht, Boston, London: Kluwer Academic Publishing, 1999:207-30.

9 For example, Andrews L, Fullarton J, Koltzmann N, Motulsky A. Assessing genetic risks, implications for health and social policy. Washington DC: National Academy Press, 1994; Nuffield Council on Bioethics. Genetic screening: ethical issues. London: Nuffield Council on Bioethics, 1993.

10 Health Council of the Netherlands (Gezondheidsraad). Erfelijkheid: wetenschap en maatschappij. Den Haag: GezondErfelijkheid: wetensch

11 Health Council of the Netherlands (Gezondheidsraad). Commissie Screening Erfelijke en Aangeboren Aandoeningen. Genetische screening, Den Haag: Gezondheidsraad, 1994.

12 See reference 9: Andrews L, et al, 1994.

13 Working Party of the Clinical Genetics Society (UK). The genetic testing of children. fournal of Medical Genetics 1994;31: 785-97.

14 Holtzman N, Watson M. Promoting safe and effective genetic testing in the United States: final report of the Task Force on Genetic testing. Baltimore: Johns Hopkins University Press, 1997.

15 Harper P. 'Over the counter'genetic testing: lessons from cystic fibrosis carrier screening. In: Harper P, Clarke A, eds. Genetics, fibrosis carrier screening. In: Harper P, Clarke A, eds. Genetics, society and clinical practice. Oxford: Bios Scientific Publishers, 1997:67-73. Bull S. Mail order gene testing. Bulletin of Medical
Ethics 1996; February: 20-1.

16 Lenaghan J. Brave new NHS? The impact of the new genetics on the health service. London: Institute for Public Policy Research, 1998

17 Post S, Whitehouse P, Binstock R, Bird T, Eckert S, Farrer L, et al. The clinical introduction of genetic testing for Alzheimer Disease (consensus statement). Fournal of the American Medical Association 1997;277:832-6.

18 Fost W. Ethical implications of screening asymptomatic individuals. FASEB fournal 1992;6:2816.

19 In the UK, most of these groups are represented on the Advisory Committee on Genetic Testing.

20 Directive of the European Parliament and the Council of 27 October 1998 on in vitro diagnostic medical devices. Official October 1998 on in vitro diagnostic medical devices. Official
fournal of the European Communities 1998 Dec 7: L331/1-L331/ 37 .

21 See reference 20: article 10

\section{News and notes \\ Journal of Medical Ethics - http://www.jmedethics.com}

Visitors to the world wide web can now access the fournal of Medical Ethics either through the BMJ Publishing Group's home page (http:// www.bmjpg.com) or directly by using its individual URL (http://www.jmedethics.com). There they will find the following:

- Current contents list for the journal

- Contents lists of previous issues

- Members of the editorial board

- Subscribers' information

- Instructions for authors

- Details of reprint services.
A hotlink gives access to:

- BMJ Publishing Group home page

- British Medical Association website

- Online books catalogue

- BMJ Publishing Group books.

The web site is at a preliminary stage and there are plans to develop it into a more sophisticated site. Suggestions from visitors about features they would like to see are welcomed. They can be left via the opening page of the BMJ Publishing Group site or, alternatively, via the journal page, through "about this site". 